\title{
Twenty-Five Years of Excellence; Respiratory Therapy in India - Past, Present, and Future
}

\author{
Jithin K. Sreedharan, Sumi Varghese ${ }^{1}$ \\ Department of Respiratory Care, Prince Sultan Military College of Health Sciences, Dhahran, Dammam, Saudi Arabia, ${ }^{1}$ Department of Respiratory Care, Kasturba \\ Medical College, Mangalore, Karnataka, India
}

\section{Abstract}

Respiratory therapy (RT) profession in India is over 25 years old. Although there have been key advancements in the profession, no history and limited evidence are available about its development and transformation. This article provides a viewpoint on the history and development of the RT field, the evolution of RT education in India, its current state, and the way forward. It also describes in brief the establishment of professional organization, scientific journal, and other major events pertinent to the RT profession in India. This article also emphasizes the need to rationalize the sector and to shape its future to suit the needs of over a billion people who utilize the services of related facilities, directly or indirectly in a highly dynamic healthcare environment. Resolutions to address a few challenges have also been considered, which in our view could be a way forward in this profession. A comprehensive review and assessment was conducted through direct communication, personal interviews, and the review of existing documents in professional organization's archives, representative hospitals, academic institutes, and other relevant texts. The data obtained were evaluated for its relevance and grouped on a thematic basis. This is currently the first paper about the comprehensive history and development of the RT profession in India over the last 25 years.

Keywords: Allied health profession, history, India, profession, respiratory care, respiratory therapy

\section{INTRODUCTION}

India's human resources for healthcare services are diverse and multi-faceted. ${ }^{[1]}$ The term "respiratory care" comprises general assessment of the patient, managing the airways, assisting and managing oxygen supplementation and mechanical ventilation, and administering aerosol medications, bronchial hygiene, chest physiotherapy, pulmonary rehabilitation, home respiratory care, and several additional modalities. These are together applied from the perspective of respiratory physiology and how it develops and disturbs patients. ${ }^{[2,3]}$ Depending on the healthcare system and clinical setting, these constituents are applied by different professions, including pulmonary physicians, anesthesiologists, intensive care specialists, emergency medical technicians, nurses, physiotherapists, and other allied health professionals. ${ }^{[4,5]}$ In recent times, this specialized subject area has emerged as a unique career path called "respiratory therapy." ${ }^{[6,7]}$ The words "interdisciplinary" and "multidisciplinary" further help to define the profession of respiratory care. ${ }^{[8]}$ The

\begin{tabular}{|l|l|}
\hline \multicolumn{2}{|c|}{ Access this article online } \\
\hline Quick Response Code: & Website: \\
& www.ijrconline.org \\
\cline { 2 - 2 } & \\
\hline
\end{tabular}

rapid growth of the population and the concomitant development of healthcare facilities have significantly impacted the progress of RT in India. ${ }^{[9]}$ The evolution of RT as a specialty has continued during the last two and a half decades. Regardless of the huge demand for services from this sector, the respiratory care domain is still highly fragmented. ${ }^{[10]}$

This paper explores the historical developments and phases of growth of the RT profession as well as its future prospects in India. This paper has a special significance as India is celebrating the Silver Jubilee Year of the RT profession in 2020 .

Address for correspondence: Mr. Jithin K. Sreedharan, Department of Respiratory Care, Prince Sultan Military College of Health Sciences, P. O. Box 33048, Dammam 31448, Saudi Arabia. E-mail: jithinksree@psmchs.edu.sa

This is an open access journal, and articles are distributed under the terms of the Creative Commons Attribution-NonCommercial-ShareAlike 4.0 License, which allows others to remix, tweak, and build upon the work non-commercially, as long as appropriate credit is given and the new creations are licensed under the identical terms.

For reprints contact: reprints@medknow.com

How to cite this article: Sreedharan JK, Varghese S. Twenty-five years of excellence; respiratory therapy in India - Past, present, and future. Indian J Respir Care 2020;9:5-11.

Received: $12-12-2019$ Accepted: 16-12-2019

Revised: $15-12-2019$ Published: 08-01-2020 
Sreedharan and Varghese: Respiratory therapy in India - Past, present, and future

\section{EARLY History}

Respiratory therapy in India was born inside hospital walls just over 25 years ago. In 1995, RT training programs were established concurrently in different parts of India. Table 1 lists some of the important events that have been most apparent to those working in this field. However, Table 1 is not all-inclusive. The journey of RT's history started when a few eminent doctors visited Loma Linda University in the USA and received international fellowships from the American Association of Respiratory Care (AARC) ${ }^{[9]}$ AARC is a prominent international organization that has been playing a silent yet substantial role in giving shape to RTs professional development in India. ${ }^{[1]]}$ One of the influencing factors was the international fellowship offered by the AARC which was established in 1990. This provided extensive opportunities for 13 physicians and one respiratory therapist from India to visit the United States and observe respiratory care as it

\begin{tabular}{ll}
\hline Table 1: Important events in the evolution of respiratory \\
therapy \\
profession in India
\end{tabular}

MCOAHS: Manipal College of Allied Health Sciences, SRMC: Sri Ramachandra Medical College, CMC: Christian Medical College, NIMS: NIZAM'S Institute of Medical Sciences, ARCI: Association for Respiratory Care-India, RTs: Respiratory therapists, RGUHS: Rajiv Gandhi University of Health Sciences, SJIC: Sri Jayadeva Institute of Cardiology, KMCH - Kovai Medical Center Hospital, SIU: Symbiosis International University, AIMS: Amrita Institute of Medical Sciences, IARC: Indian Association of Respiratory Care, IJRC: Indian Journal of Respiratory Care, BSc: Bachelor of Science, RCT: Respiratory care technology is practiced there. ${ }^{[12]}$ Those well-experienced clinicians who returned after the fellowship from AARC became advocates of the profession.

\section{Educational Programs and Structure}

Despite commencement of these programs around the same time, the curricula differed in their structure and duration. Due to lack of uniform nomenclature and qualified faculty, diverse curriculum design posed a gigantic threat to the quality of education and skills of respiratory therapists. Differences prevailed in entry-level qualifications as well. Barring a few well-recognized central universities and autonomous institutes, many lacked adequate educational resources such as libraries and simulation centers among many other basic amenities. ${ }^{[13]}$ Poor faculty retention policies and absence of workforce expansion posed great challenges to the quantity and quality of training. ${ }^{[1]}$ Nevertheless, training and learning advancements went through a slow period from the beginning until the mid-2000s. Subsequently, a vast expansion and revolution in the education of the RT profession happened. This expansion has posed fresh challenges and has been coupled with a tremendous need for formal education, training in the clinical practice, and theoretical basis of the profession. ${ }^{[14]}$ Today, India has over 21 colleges affiliated with government and autonomous universities offering RT programs. These are located mainly in the states of Maharashtra, Karnataka, Kerala, Tamil Nadu, Andhra Pradesh, and Telangana.

\section{Diploma programs}

In 1996, Christian Medical College (CMC), Vellore, established a diploma program in respiratory therapy with a duration of 2 years followed by a 1-year internship. The course structure consisted of anatomy, physiology, and RT sciences along with rigorous clinical training. Four students enrolled in the first batch. The course was later converted to a postgraduate diploma (PG. Dip) in advanced respiratory therapy. There was no change in the duration of the program, but they limited the entry-level qualifications to a bachelor's degree in the sciences or health sciences. Pulmonary function testing (PFT) procedures and polysomnography were added to the existing curriculum. However, this course was continued only for few years.

In 1997, the Nizam's Institute of Medical Sciences, Hyderabad, introduced a 2-year PG. Dip program named respiratory therapy technology. ${ }^{[15]}$ There were three seats, and the course syllabus included anatomy and physiology, applied physiology, respiratory care equipment, gas physics, and basic life support. These courses were done in the $1^{\text {st }}$ year, and they were followed by pharmacology, respiratory diseases, disease management and related procedures, and intensive care unit (ICU) monitoring in the $2^{\text {nd }}$ year. The course still runs with an annual intake of 11 students.

In 2002, Kovai Medical Centre and Hospital $(\mathrm{KMCH})$-Coimbatore started a PG. Dip in respiratory therapy as 1-year program. However, it lasted for only 3 years. 
Later, in 2008, they restarted the PG. Dip in respiratory care management with Bharathiyar University. It had an intake of 10 students and was sustained for the following 3 years. Over these years, nearly 24 PG. Dip holders graduated from KMCH.

In 2011, the Government Medical College, Calicut, introduced a diploma in respiratory technology. It was an annual scheme for 2 years followed by a 6-month internship. The students were trained in critical care, emergency department, and PFT laboratories. The course continues to this day, and it is the only government-run institute to offer a diploma in respiratory therapy to date. ${ }^{[16]}$

\section{Bachelor's program}

In 1995, Manipal University, currently known as Manipal Academy of Higher Education (MAHE), and Sri Ramachandra Institute of Medical Sciences (SRMC) spearheaded the structured respiratory therapy course in India. However, the course at MAHE focused solely on respiratory therapy, whereas SRMC designed a BSc Allied Health Sciences program encompassing 15 various vital professions in the medical field, with respiratory care technology (RCT) being one of them. MAHE's course structure was based on a combination of the 1- and 2-year programs in the USA which commenced as a 3 -year program and culminated in a 4-year program with a 1-year compulsory internship. ${ }^{[17]}$ SRMC followed a 4-year structure from the beginning. The candidates who completed higher secondary education or equivalent courses were eligible to enroll for both. The main difference observed is the nomenclature. At SRMC, this program is still called RCT. ${ }^{[18]}$

In 1999, Rajiv Gandhi University of Health Sciences (RGUHS), an eminent government university in Karnataka, introduced the course along with many other allied health specialties (AHP). Sri Jayadeva Institute of Cardiology was the first to incorporate this allied health profile into their academic affairs. It was a 3 -year program followed by 6 months of a rotatory internship. From 2010 to 2018, many other medical colleges affiliated with RGUHS, after identifying the scope and demand for AHP, started allied health divisions in their institutions. Along with that cluster, respiratory therapy was initiated. This university now has 10 affiliated respiratory therapy programs and graduates nearly 200 RTs per year. ${ }^{[19]}$ Recently, the duration of the course was revised, and now it is a 4-year course with a 1-year internship.

In 2006, Symbiosis International University (SIU), Pune, established a graduate-level program BSc Medical Technology with 3 years of coursework. This course was similar to the SRMC program, and students in their third semester were segregated based on merit to their respective specialization from the pool of allied health enrollment. RCT was one of the six specializations. ${ }^{[20]}$ This is the only course running in the central part of India.

In 2010, Amrita Institute of Medical Sciences (AIMS), affiliated with Amrita Viswavidyapeetham University, opened its gates for a 4-year BSc RT program, and the eligibility criteria were similar to its counterparts. ${ }^{[21]}$ In 2012, the earlier diploma program at $\mathrm{KMCH}$ was upgraded to a bachelor's program offered by the Tamil Nadu Dr. MGR University. ${ }^{[22]}$ It commenced with a duration of 3 years and was subsequently restructured to 4 years. ${ }^{[23]}$ The RT program from the Tamil Nadu Dr. MGR University was also adopted by CMC, Vellore, in the same year.

India's BSc RT programs are largely similar, but they differ in consistency and nomenclature. Basic science subjects such as anatomy, physiology, biochemistry, microbiology, and pharmacology are taught in the $1^{\text {st }}$ year, followed by respiratory and cardiovascular diseases, diagnostic techniques, respiratory care equipment, respiratory care procedures, and biostatistics in the $2^{\text {nd }}$ year. The $3^{\text {rd }}$ year is comprised of topics such as cardiopulmonary rehabilitation, mechanical ventilation, critical care management, and other diagnostic methods. Figure 1 shows graduate and postgraduate programs in India.

\section{Master's program}

In 2006, MAHE expanded the scope of the profession by starting a 2-year master's program (MSc) with two specializations: adult respiratory care and neonatal and pediatric respiratory care. There was some reluctance exhibited in the early stages by graduates. Along with the extended respiratory therapy curriculum, the university was keen on research papers, and thus, more focus was shifted toward research and evidence-based practices. ${ }^{[17]}$ AIMS started its master's program in 2010. They too had similar subspecialties and structure, with a focus on leadership, management, and research. ${ }^{[21]}$ Earlier this year, SRMC, Srinivas University, and Dr. MGR University instituted master's program in their respective institutes.

\section{PhD program}

In 2009, MAHE crossed another milestone by opening a $\mathrm{PhD}$ program. Now, there are numerous universities offering $\mathrm{PhD}$ programs in allied health with respiratory therapy as subspecialty. AIMS and Srinivas University-Mangalore are two examples.

\section{Novel Beginning of the Professional Organization}

In 1998, a small group of respiratory therapists under the leadership and guidance of Dr. R. Vijay Kumar, a

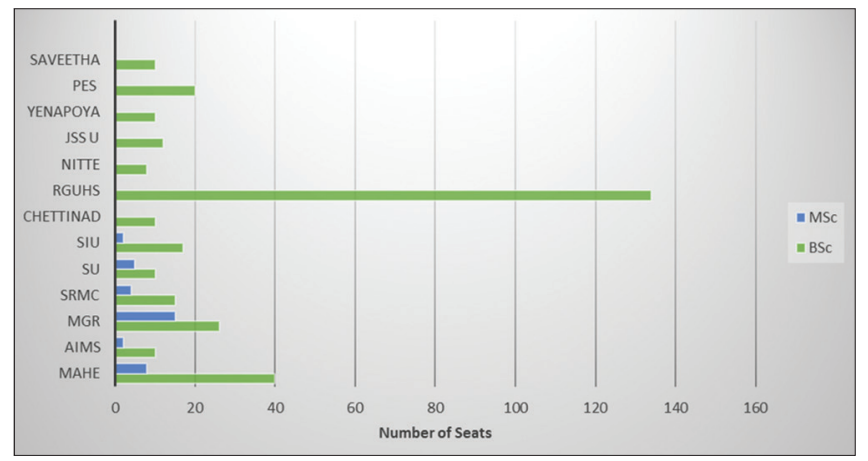

Figure 1: Current educational programs in India and number of seats. MSc: Master of Science, BSc: Bachelor of Science, JSS: Jagadguru Sri Shivarathreeshwara University, SU: Srinivas University 
Sreedharan and Varghese: Respiratory therapy in India - Past, present, and future

leading pulmonologist from Hyderabad and a recipient of international fellowship of AARC in 1992, formed an association and named it the association for respiratory care India. This was done under the patronage of a few prominent local hospitals in Hyderabad. ${ }^{[9]}$ Dr. Vijay Kumar was elected as the founding president of the society. The primary aim was to bring all respiratory therapists (RTs) together onto one platform and to empower and regularize the education and RT practice in the country. With a visionary approach to leadership and with the incredible support of advisory board members, ARCI organized the first scientific conference "RESCARE" in 2006 at CMC.

In a meeting held during the Second Annual Conference held at SRMC Chennai, the office bearers requested a more formal organizational structure and to formulate constitution for the society. In 2011, ARCI became formally recognized as the present "Indian Association of Respiratory Care (IARC)" and registered under the Karnataka Society Act 1960. The head office is at the Department of Respiratory Care at MAHE. Up until this year, IARC organized 13 national conferences uninterruptedly under the unique name "RESCARE" [Table 2]. ${ }^{[2]}$ These conferences undoubtedly provided an early forum for the educational and political expression of the new organization.

A conference on the scientific root of respiratory therapy, by a group of enthusiastic RTs from the Kochi region, was convened in October 2017. Numerous well-known RTs from around the nation met and reviewed the progress of the profession and future plans. 2017 Kochi RESCARE was a landmark conference in the history of IARC. A record-breaking number of delegates and faculties joined together under the leadership of the then-president of IARC, Dr. Suresh G. Nair. Without further questions, the new office bearers ushered in a new era. A new organizational strategy of member control was introduced, and in so doing, positive membership and practitioner growth were evident in the subsequent years. The society had a new strategic goal and a distinct mission for unifying professional standards, unique curriculum development, and credentialing. ${ }^{[25]}$ Table 3 lists historical moments observed in the progress of IARC.

\section{The Birth OF the Indian Journal of Respiratory Care}

In 2012, with the determined and profound efforts of Dr. Anita Shenoy, a renowned anesthesiologist from Kasturba Medical College (KMC), and with the collective support of Manipal University, IARC launched its prestigious scientific journal. The Indian Journal of Respiratory Care (IJRC) was established with the aim of reassuring the scientific contributions of RTs in the country. IJRC is now an indexed, peer-reviewed, fully accessible online semi-annual journal with more than 20,000 users. ${ }^{[26]}$ Being IARCs flagship publication, this journal is a response to the challenges in clinical practice, changing the face of education, and research specifically tailored for practicing respiratory therapy.

\begin{tabular}{ll}
\hline \multicolumn{2}{l}{ Table 2: RESCARE venues and year } \\
\hline Years & Host/venue \\
\hline 2006 & CMC - Vellore \\
2007 & SRMC - Chennai \\
2008 & MCOAHS - Manipal \\
2009 & DMH - Pune \\
2010 & ISCCM - Hyderabad \\
2011 & MCOAHS - Manipal \\
2012 & CMC - Vellore \\
2013 & AIMS - Kochi \\
2014 & Pune \\
2015 & KMCH - Coimbatore \\
2016 & CMC - Vellore \\
2017 & Kochi \\
2018 & NH - Bangalore \\
2019 & AJIAHS - Mangalore \\
\hline ISCCM: Indian Society of Critical Care Medicine, AJIAHS: AJ Institute \\
of Allied health Sciences, NH: Narayana Hrudayalaya, DMH: Deenanath \\
Mangeshkar Hospital, CMC: Christian Medical College, SRMC: Sri \\
Ramachandra Medical College, MCOAHS: Manipal College of Allied \\
Health Sciences, AIMS: Amrita Institute of Medical Sciences, KMCH - \\
Kovai Medical Center Hospital
\end{tabular}

\begin{tabular}{ll}
\hline \multicolumn{2}{l}{ Table 3: Historical moments in the organization } \\
\hline Years & Event \\
\hline 1998 & Beginning of ARCI \\
2006 & Organizing the first annual conference \\
2007 & Elected office bearers and developing constitution \\
2011 & Registering the society \\
2012 & First copy of IJRC is published \\
2017 & IJRC is accepted for indexing, and collaborating \\
& with Wolter-Kluwer www.ijrconline.org \\
2017 & Launch of unique web portal www.iarc.in and \\
& online member management suite \\
2017 & Establishing new organizational strategy and policy \\
2018 & Announcing credentialing - CRTP \\
\hline ARCI: Association for Respiratory Care-India, IJRC: Indian Journal of \\
Respiratory Care, CRTP: Certified Respiratory Therapy Professional
\end{tabular}

\section{RESPIRATORY TheraPy WORKFoRCE IN INDIA}

The RT profession in India is still in its embryonic stage. Shevade et al. in their recently concluded cross-sectional observational study lay emphasis on the fact that a vast majority of RTs $(68 \%)$ work in ICUs or acute care facilities, and the remaining are functioning in pulmonary function laboratories, sleep laboratories, home care and private companies, and teaching facilities. ${ }^{[10]}$ She also revealed the interesting fact that $90 \%$ of Indian RTs hold a baccalaureate or higher degree in respiratory therapy and $<10 \%$ of them are diploma holders in RT or on-the-job job trainees with different educational backgrounds. An internal quality survey conducted by the professional organization discloses identical results, where they also recognized the mean age of Indian RTs at $28 \pm 4$ years. Most of the RT workforce is concentrated in the southern part of the country, and nearly 1000 RTs are functioning in aggregate. ${ }^{[27]}$ A precise number 
of committed RTs in the country are unavailable since there is no registry other than the professional organization's records. In addition, no study has been done in this regard. However, India, being a large country both in size and population, offers every trained respiratory therapist the opportunity to go to different parts of the country and either commence a respiratory therapy course or be a good ambassador to the new professional group. ${ }^{[28]}$

\section{Professional Regulation and Accreditation}

With the innovations in medicine and technologies, there has been a quantum leap in the demand for respiratory therapists in the country. This has taken place in conjunction with the exponential growth of the private health sector since 1949 , presently accounting for $93 \%$ of hospitals and $85 \%$ of doctors in India. ${ }^{[29]}$ Interestingly, $95 \%$ of RTs in India are employed in the private sector as well. ${ }^{[27]}$ This has resulted in the establishment of an enormous number of institutions and universities for training, a vast majority of which are run without any regulation and control over quality and with minimum standards of education. The purpose of respiratory care regulation is to safeguard the people's well-being and safety by establishing minimum qualifications and creating exclusive designations corresponding to the level of qualifications for those who wish to offer respiratory care services to the public. ${ }^{[30]}$ Given the crucial role that any allied health professional has, especially the role that RTs play in healthcare delivery, maintenance of appropriate and minimum standards in their training and education is essential. ${ }^{[31,32]}$ Besides the primary responsibility of defining the scope of the profession (e.g., what procedures RTs can perform and what cannot), the regulatory body shall be accountable for setting requirements for entering and practicing in the profession and shall be an authority to maintain the registry and use the title of respiratory therapist. ${ }^{[33]} \mathrm{An}$ accreditation or certification board has turned into a compulsory prerequisite for a number of specialty fields in many clinical settings in India. ${ }^{[34]}$ It can also be used as a quality indicator. ${ }^{[35]}$ The knowledge and skills of the clinicians play a substantial role in terms of the prevention or mitigation of complications and the reduction of risk to causing harm to patients. ${ }^{[36]}$ The RT profession in India is currently lacking an accreditation body with a credentialing system, and it is imperative that one be established.

\section{The Future of the Respiratory Therapy Profession In InDIA}

RTs shall prepare themselves to play a larger and more expanded role in hospitals and educational facilities. Proactive and young RTs can identify and take huge advantage of the broad scope of practice. ${ }^{[37,38]}$ RTs have begun to assume new responsibilities and have been asked to take a larger supportive role as adjuncts to traditional nursing functions. This has been largely due to the shortage of doctors and nurses. A systematic approach and implementation to research-oriented, evidenced-based protocols, and best practices is an important proficiency required to take up this challenge. ${ }^{[7]}$ Respiratory insufficiency and comorbid conditions have been reported to be the leading cause $(36 \%)$ for activation of emergency calls, and this observation is now triggering the hospital authorities to identify RTs as an integral part of the code blue team. This code blue team can make a difference by refining ventilation and oxygenation, thus minimizing further complications and adding intensive care cost. ${ }^{[39]}$

India is a big country with more than 1.25 billion people, and bearing in mind the amount of diverse clinical exposure in our country and the number of teaching institutions, there is a huge potential for enhancing research in the field of respiratory therapy. ${ }^{[40]}$ Apart from original articles, case reports of rare cases, audits, surveys, and review articles should also be considered for publishing. Today's leaders should instill and nurture a research-oriented practice in their capacities and make use of IJRC to achieve its mission. ${ }^{[41]}$

The most awaited allied health professional bill will provide RTs with an advanced role in patient care and facilitate the RT services. ${ }^{[42]}$ These services may include in-patient and outpatient respiratory care services and monitoring based on professional consultations, training, assessment, and treatment under the directions and supervision of a qualified medical practitioner ${ }^{[43]}$ Figure 2 illustrates the constituents of regularization process.

\section{Discussion}

The healthcare system in India is on the verge of a dramatic change. ${ }^{[44]}$ The emerging policies are focused on finding ways to decrease costs and improve quality. ${ }^{[4]}$ The vision and mission statement by the Ministry of Health and Family Welfare have given precedence to developing training and human resources in health services. ${ }^{[46]}$ Globally, healthcare reformation policies are finding ways to keep patients away

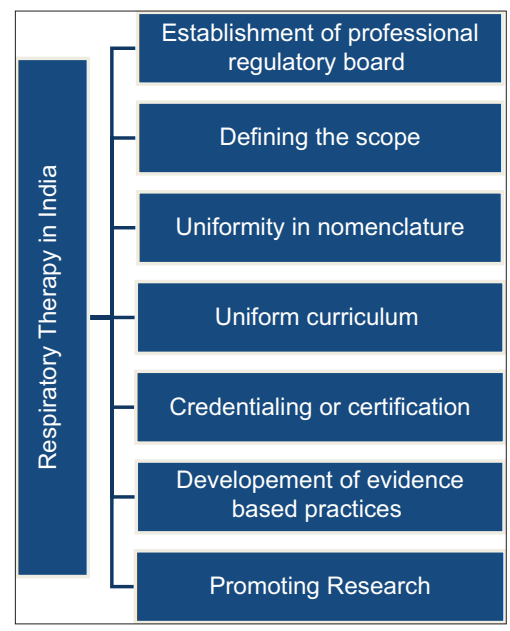

Figure 2: The road map to outline the respiratory therapy profession in India 
from costly inpatient care and offer services in a less expensive setting. ${ }^{[45]}$ It will be highly impactful if RTs can expand their scope beyond the hospital walls to areas, such as home respiratory care and small-scale intensive care settings in rural areas. This has the ability to deliver effective interventions that keep our patients healthy even out of the hospital. ${ }^{[4]}$ The RT leadership team, in collaboration with government authorities and hospital facilities, should identify innovative ways to educate and treat patients outside of the hospital setting instead of waiting for patients to approach the hospital for care. ${ }^{[48]}$ It is a known fact that there is currently a problem with brain drain affecting respiratory care, nursing, and other professions in India. Indian RTs are especially in high demand in the gulf region. This is good up to a certain level since it brings a good exchange of knowledge. However, financial incentives, higher salaries, retention policies, and establishing a career ladder will help to hold respiratory therapists back in India. It is certain that RT is an indispensable element of the modern health care system that has enormous potential. ${ }^{[49]}$ Professional organizations and pioneer respiratory therapists who work in the country and abroad have a pivotal role in shaping this challenging career. They must evolve to meet the requirements of the future workforce. ${ }^{[50]}$ In 2020, when India celebrates its Silver Jubilee of the inception of the RT profession, we have a reason to be optimistic.

\section{Acknowledgments}

"Extending our deep gratitude to the incredible community of pioneer respiratory therapists who illuminated the path forward, guiding our understanding of how respiratory therapists (RTs) could support the patients, their desires, and even dreams. You have molded us for what we are today and demonstrated the true meaning of compassion and care. We look forward to the next 25 years and more"

We would like to thank Dr. Ramkumar Venkateswaran, Dr. Anita Shenoy, Dr. Vijay Kumar, Dr. Suresh G. Nair, Dr. D. J. Christopher, Dr. J. V. Peter, Dr. Parimala Prasanna Simha, Dr. Manjush Karthika, Dr. Saumy Johnson, Dr. Sachin, Dr. Sudhesh Rao, Dr. T. Vijayalaskhmi, Prof. Vijay Deshpande, Ms. Madhuragauri Shevade, Ms. Kumari Sulochana, Mr. Premandand Johnson, Mr. Radhakrishnan Nair, Mr. Amal Joseph, Mr. Arthur Sadhanandham, Ms. Anita Patil, Mr. Narasimha Murthy, Ms. Mangal Raj Arun, Ms. J. Saranya, Mr. Sri Harsha Tatineni, Ms. J. Jeny, Ms. Girija Vijaykumar, Dr. K. S. Lokesh for their valuable contribution to the manuscript. Thanks to Mr. Nikolos for proofreading this document. Sincere thanks to Dr. Mohammed AlAhmari, Dr. Saad AlRaeeah and my friend Mr. Abdullah Ghazwani for instilling intrinsic motivation.

\section{Financial support and sponsorship}

Nil.

\section{Conflicts of interest}

There are no conflicts of interest.

\section{RefERENCES}

1. Sahni A. Production and Utilization of Health Manpower towards Improvement of Health Services in India Health Administrator. 2005;17: p. 1-3. Available at: http://medind.nic.in/haa/t05/i2/haat05i2p1.pdf. [Last accessed on 15 Dec 2019].

2. Mishoe SC, MacIntyre NR. Expanding professional roles for respiratory care practitioners. Respir Care 1997;42:71-91.

3. The Lewin Group. Respiratory Care Practitioners in an Evolving Health Care Environment. Dallas, TX: Association for Respiratory Care; 1997.

4. Stoller JK. Misallocation of respiratory care services: Time for a change. Respir Care 1993;38:263-6.

5. Kester L, Stoller JK. Ordering respiratory care services for hospitalized patients: Practices of overuse and underuse. Cleve Clin J Med 1992;59:581-5.

6. Rashid S. Who are respiratory therapists? J Lung Pulm Respir Res 2014;1:118-9.

7. Pierson DJ. The future of respiratory care. Respir Care 2001;46:705-18.

8. Rickards T, Kitts E. The roles, they are a changing: Respiratory Therapists as part of the multidisciplinary, community, primary health care team. Can J Respir Ther 2018;54:83-5.

9. Ratnavelu VK. Respiratory therapy in India. Indian J Respir Care 2012;1:8-10.

10. Shevade M, Madas S, Chorghade M, Kesav K, Biswas A, Yeravdekar R, et al. Demographics and competencies of respiratory therapists across India: A cross-sectional observational study. Respir Care 2019;64:3234628.

11. Deshpande V. Respiratory therapy - Global scenario. Indian J Respir Care 2012;1:3-7.

12. ICRC Links. Retrieved from: Available from: https://www. arcfoundation.org/donations-and-support/support-for-international-fell owships/\#arcf-previous-fellows. [Last accessed on 2019 Dec 24].

13. Gaur V. An Overview of redefining paradigm: India's Allied Health Professional. Int J Biochem 2018;1:20-34.

14. Venkateswaran R. Importance of uniformity in education, continuing education and preparing tomorrow's leaders. Ind J Resp Care 2012;1:11-4.

15. Nizam's Institute of Medical Sciences. Academic Section II. Available from: https://www.nims.edu.in/academic_section2. [Last updated on 2019 Dec 08].

16. Government Medical College. Pulmonary Medicine. Available from: https://www.govtmedicalcollegekozhikode.ac.in/icd. [Last updated on 2019 May 25].

17. School of Allied Health Sciences. BSc Respiratory Therapy. Available from: https://manipal.edu/soahs-manipal/programs/program-list/ bsc-respiratory-soahs.html [Last updated on 2019 Dec 08].

18. Sri Ramachandra Institute of Higher Education and Research. Allied Health Sciences. Available from: https:/www.sriramachandra.edu.in/ university/academics.php?did=82 [Last updated on 2019 Dec 08].

19. Rajiv Gandhi University of Health Sciences, Karnataka. Allied Health Sciences. Available from: http://www.rguhs.ac.in/courses_rguhs. html\#10. [Last accessed on 2019 Dec 20].

20. Symbiosis Institute of Health Sciences. Bachelor of Science (B. Sc.) Medical Technology. Available from: https://www.sihspune.org/ bsc-medical-technology.php. [Last updated on 2019 Dec 08].

21. Amrita Vishwa Vidyapeetham University. B.Sc. (Bachelor of Science) in Respiratory Therapy. Available from: https:/www.amrita.edu/ admissions/bsc-allied-healthsciences-2020/eligibility. [Last accessed on 2019 Dec 24].

22. KMCH Institute of Allied Health Sciences. Available from: http://www. kmchahs.ac.in/courses.php. [Last updated on 2019 Dec 08].

23. The Tamil Nadu MGR Medical University, Allied Health Sciences. Available from: https://www.tnmgrmu.ac.in/index.php/courses/ allied-health-sciences.html. [Last accessed on 2019 Dec 24].

24. The Indian Association of Respiratory Care (IARC), Annual Conference-RESCARE. Available from: http://rescare.iarc.in/. [Last accessed on 2019 Dec 15].

25. The Indian Association of Respiratory Care (IARC). About IARC Profile. Available from: http://iarc.in/mission_vision. [Last accessed on 2019 Oct 15]. 
26. Indian Journal of Respiratory Care. About IJRC Profile. Retrieved from: Available from: http://www.ijrconline.org/aboutus.asp. [Last accessed on 2019 Dec 15].

27. Indian Association of Respiratory Care. Member satisfaction survey reports. Available from: https://www.youtube.com/ watch?v=Dp1F3D7Us7o. [Last accessed on 2019 Dec 24].

28. Shenoy A. Respiratory therapy in India: Another step forward. Indian J Respir Care 2012;1:1-2.

29. Khandekar S. Health care within the common man's reach. Prayas 2011;1:21.

30. The Philippine Respiratory Therapy Act of 2009. Available from: https:// www.prc.gov.ph/sites/default/files/Respiratory\%20Therapy\%20-\%20 Implementing\%20Rules\%20and\%20Regulation_0.pdf. [Last accessed on 2019 Dec 24].

31. Mele J. Guidelines and recognition needed for respiratory therapists. J Burn Care Rehabil 1983;4: 10.

32. Barnes TA, Gale DD, Kacmarek RM, Kageler WV. Competencies needed by graduate respiratory therapists in 2015 and beyond. Respir Care 2010;55:601-16.

33. Kollef MH, Watts P. Moving the practice of respiratory therapy forward. Respir Care 2019;64:1014-6.

34. The Kerala Paramedical Council Bill; 2002. Available from: http://www. keralalawsect.org/law_cms/index.php/law-reforms-committee/132. [Last accessed on 2019 Dec 24].

35. Becker EA, Nguyen XT. The current impact of entry-level associate and baccalaureate degree education on the diversity of respiratory therapists. Respir Care 2014;59:1817-24.

36. Kendall-Gallagher D, Blegen MA. Competence and certification of registered nurses and safety of patients in intensive care units. J Nurs Adm 2010;40:S68-77.

37. Barnes TA, Kacmarek RM, Kageler WV, Morris MJ, Durbin CG Jr. Transitioning the respiratory therapy workforce for 2015 and beyond. Respir Care 2011;56:681-90.

38. Sreedharan JK, Alqahtani JS. Driving pressure: Clinical applications and implications in the intensive care units. Indian J Respir Care
2018;7:62-6.

39. Sharek PJ, Parast LM, Leong K, Coombs J, Earnest K, Sullivan J, et al. Effect of a rapid response team on hospital-wide mortality and code rates outside the ICU in a children's hospital. JAMA 2007;298:2267-74.

40. Rice R, Stoller JK. Respiratory therapists' role in research: Results of a national survey. Indian J Respir Care 2013;2:339-45.

41. Shenoy A, Unnikrishnan R. Research-make in India? Indian J Respir Care 2016;5:669-70.

42. Ministry of Health, Family Welfare, Government of India. The Allied Health Professional Bill. Ministry of Health, Family Welfare, Government of India; 2018. Available from: https://www.prsindia.org/ billtrack/allied-and-healthcare-professions-bill-2018. [Last accessed on 2019 Jan 08].

43. Dubbs WH, Weber K. AARC survey measures effects of restructuring on respiratory care nationwide. AARC Times 1996;3:29-40.

44. Singh R. Integrated Healthcare in India-A Conceptual Framework. Ann Neurosci 2016;23:197-8.

45. Becker EA, Hoerr CA, Wiles KS, Skees DL, Miller CH, Laher DS Utilizing respiratory therapists to reduce costs of care. Respir Care 2018;63:102-17.

46. Ministry of Health, Family Welfare, Government of India. Vision and Mission Statement. Available from: https://mohfw.gov.in/Documents/ vision-mission-and-objective-statement-mohfw. [Last accessed on 2019 Apr 30].

47. Edge R, Mathews PJ. The history and scope of practice of respiratory care. In: Wyka K, Mathews PJ, Clark W, editors. Fundamentals of Respiratory Care. Albany, NY: Delmar Thompson Learning; 2002.

48. Myers TR. Thinking outside the box: Moving the respiratory care profession beyond the hospital walls. Respir Care 2013;58:1377-85.

49. Stoller JK. The rationale for respiratory care protocols: An update. Respir Care 1998;43:719-23.

50. Smith SG, Endee LM, Benz Scott LA, Linden PL. The future of respiratory care: Results of a new york state survey of respiratory therapists. Respir Care 2017;62:279-87. 